\title{
Artificial Insemination in Sheep with Fresh Diluted Semen: Comparison Between Two Different Semen Extenders and Management Protocols
}

\author{
A. Madrigali ${ }^{a, *}$, A. Rota ${ }^{a}$, D. Panzani ${ }^{a}$, S. Castellani ${ }^{b}$, M. Shawahinac ${ }^{c}$ A. Hassanc, F. Di Iacovo ${ }^{a}$, C. \\ Rossignolia ${ }^{a}$ \& F. Camillo ${ }^{a}$ \\ aDepartment of Veterinary Sciences, University of Pisa, Via Livornese snc, 56122 San Piero a Grado, Pisa, Italy \\ boxfam Italy, Via Pierluigi da Palestrina, 26, 50144 Firenze, Italy \\ c Palestinian Livestock Developing Centre - al-Dakaneeh area, Tubas, West Bank. \\ ${ }^{*}$ Corresponding author: alessio.madrigali@phd.unipi.it \\ (Received 13-08-2020; Revised 16-11-2020; Accepted 15-12-2020)
}

\begin{abstract}
Timed artificial insemination (TAI) is a very important tool for reproductive programs in small ruminants, providing synchronized inseminations and more efficient use of superior males. The objectives of this study were to investigate the viability of different breeding protocols under suboptimal conditions and out of the breeding season, and to compare the outcome of TAI in sheep with two different semen extenders. Ewes $(n=575)$ were subjected to estrous synchronization by intravaginal sponges containing $30 \mathrm{mg}$ of medroxyprogesterone acetate and PMSG. Ewes were divided into 5 groups according to the semen extender employed and to the breeding protocol: 1) egg yolk citrate AI reinforced by ram (EYC-RR); 2) Andromed AI reinforced by ram (AND-RR), where rams joined the flocks 3 hours after AI; 3) egg yolk citrate AI without ram exposition (EYC); 4) Andromed AI without ram exposition (AND). In all these groups vaginal AIs were performed $56 \pm 2$ hours from sponge removal and PMSG injection; 5) natural mating (RAM) where rams were introduced 48 hours following sponge removal and PMSG injection. Pregnancy rate, parturition rate, and prolificacy were significantly higher $(p<0.05)$ in the EYC-RR and AND-RR groups than in the EYC and AND groups. The lambing rate was not different between groups. No statistical differences were observed between breeding farms or inseminating rams. This study showed that TAI with fresh semen diluted either with egg yolk citrate or with AndroMed could be an effective and feasible tool to increase lamb production and improve genetic merits of the sheep population out of the breeding season.
\end{abstract}

Keywords: sheep; out of season; artificial insemination; natural mating; west bank

\section{INTRODUCTION}

Around $22 \%$ of the Palestinian population in the West Bank (WB) are food insecure (WFP and FAO, 2010). Livestock production contributes roughly to $46 \%$ of agricultural income in the $\mathrm{WB}$, where are reared around 672,000 sheep and 226,000 goats, which are $60 \%$ of the total livestock of the WB (Palestinian Central Bureau of Statistics, 2013). According to the Palestinian Central Bureau of Statistics (PCBS), in 2013, 58\% of the sheep in WB were Awassi while the rest was represented by Assaf and crossbred. The fat-tailed Awassi sheep is the most common breed in the Middle East countries, where it is used for meat, milk, and wool production. Sheep of this breed have an increased resistance to diseases and parasites, the ability to walk long distances for grazing and tolerance to paucity of available food, and high adaptation to desert climates (Gootwine, 2011). The natural breeding season of Awassi sheep is concentrated during late June through early September, which allows ewes to lamb between late November and early February (Talafha \& Ababneh, 2011).
Assaf sheep is the result of a cross-breeding program, initiated in 1955, between the improved Israeli Awassi and the German East Friesian breed, and contains $3 / 8$ of the improved Israeli Awassi and 5/8 of the German East Friesian. The Assaf sheep is today considered a high-producing dairy and mutton breed, well adapted to the intensive management system. The average milk production of Assaf sheep under intensive management conditions can reach 400 liters per lactation, with an average prolificacy of 1.6 lambs per lambing. Other traits that characterize the half fat tail Assaf breed are its large body (a ram can weigh as much as $120 \mathrm{~kg}$ ), relatively short anestrous period, and the lambs' excellent growth ability (Gootwine, 2011).

Artificial Insemination (AI) at a fixed time or Timed Artificial Insemination (TAI) is an important tool for reproductive programs in small ruminants, allowing more efficient use of superior males and reducing the labor necessary for estrous detection, but requires precise synchronization of ovulation and satisfactory pregnancy rates (Baril et al., 1993; Martin \& Ferasyi, 2016). 
The most widespread protocols employed to synchronize estrous and ovulation for TAI in ewes are based on progesterone treatments, usually associated with PMSG administration (Fleisch et al., 2015). These synchronization protocols are usually based on the insertion of progestagen-impregnated intravaginal sponges for 12-14 days, followed by the intramuscular injection of PMSG at sponges removal (Abecia et al., 2012). The application of progestogens is considered to improve sperm transport and survival, the pattern of LH secretion, and the quality of the corpora lutea, determining an overall enhancement of ewes fertility (GonzalezBulnes et al., 2020).

Palestinian Livestock Development Centre (PLDC) practices out of season estrous synchronization and TAI in WB to obtain earlier parturition and the spread of Assaf genetic traits on a sheep population based mostly on Awassi and crossbred. Routine PLDC protocol consists of diluting semen with an egg yolk citrate based medium and to introduce rams in ewes' flock three hours after AI. This approach maximizes the reproductive performances of the inseminated ewes but makes it impossible to know if pregnancies were due to the AI or to the natural mating, compromising the possibility of a genetic improvement program.

Egg yolk-based semen extenders have been universally used for cryopreservation of semen from livestock species, including sheep (Islam \& Khan, 2010; Stefanov et al., 2015). However, the quality of egg yolk may differ according to the time of storage, and high egg yolk concentrations could reduce the post-thawing viability of ejaculated spermatozoa in rams and goats (Zamiri, 2020). Moreover, the use of animal components in semen extenders is consistent with potential hygienic risks (Khalifa et al., 2013). Therefore, the development of a synthetic semen extender free of animal sources has been desired. A relatively new commercial soybean lecithin-based extender (AndroMed, Minitübe, Tiefenbach, Germany), without egg yolk or other animal-derivate elements, has been developed and successfully used for cryopreservation of semen of several species, including bovine (Layek et al., 2016), North American bison (Krishnakumar et al., 2011), and sheep (Khalifa et al., 2013; Masoudi et al., 2017). Soybean lecithin has shown the capacity of protecting the plasma membrane of ram spermatozoa against the negative effects of reactive oxygen species formed during cryopreservation (Masoudi et al., 2017).

Although many different protocols have been developed for TAI in sheep, scant information is available on feasible and efficient TAI protocols under suboptimal field conditions. Therefore, the aims of the present study were 1) to evaluate the effectiveness and feasibility of different breeding protocols under sub-optimal conditions and out of the breeding season in WB, 2) to compare the outcome of TAI in sheep with fresh semen diluted either with egg yolk citrate or with AndroMed and with or without the exposition of ewes to rams three hours after TAI.

\section{MATERIALS AND METHODS}

\section{Animals}

A total of 575 Awassi, Assaf or Awassi x Assaf crossbred (crossbred) ewes, between 1 and 5 years of age, owned by 33 different farmers, located between Jenin and Jericho, in WB, were used. The study was done during non-breeding season (March and April). All the ewes were clinically healthy, at least at 60 days post-partum, with a good body condition score. Animals were grazed on natural pastures during the day and kept in the pen at night, where they received a supplement of $0.5 \mathrm{~kg} /$ day of concentrates and ad libitum access to water. Clean water was also provided on pasture by mobile water tanks. The study was approved by the Institutional Animal Care and Use Committee of the University of Pisa (OPBA, Pisa, approval no 13/21, 19/03/2021).

\section{Experimental Groups}

All the ewes included in the study were synchronized using intravaginal sponges containing 30 mg of Medroxyprogesterone Acetate (Syncro-part sponges $($ ) for 14 days followed by IM injection of 600 IU of PMSG (Syncro-part PMSG®, Ceva Santé Animale, Libourne, France) at sponges removal. Ewes were then divided into five (5) groups according to the semen extender employed and to the breeding protocol: egg yolk citrate AI without ram introduction (EYC, n=132), Andromed AI without ram introduction (AND, n= 201), egg yolk citrate AI reinforced by ram (EYC-RR, n=123), Andromed AI reinforced by ram (AND-RR, $n=79$ ), and natural mating (RAM, n= 40). In the EYC and AND groups, vaginal AIs were performed at $56 \pm 2$ hours after sponges' removal and PMSG injection, using a volume of $0.3 \mathrm{~mL}$ of fresh semen diluted with egg yolk citrate and Andromed, respectively. AIs were performed by experienced technicians using a $1 \mathrm{~mL}$ serological pipette and semen $\left(200 \times 10^{6}\right.$ spermatozoa) was deposited in the entrance of the cervix. In the EYC-RR and AND-RR groups, vaginal AIs were performed in the same manner as EYC and AND groups, but the ewes were also exposed to rams 3 hours after AI. Finally, in the RAM group, AI was not performed, and rams were joined to ewes 48 hours after sponges' removal and PMSG injection. In the RAM, EYC-RR, and AND-RR groups, natural mating was performed using sexually experienced and fertile Crossbred rams directly owned by the farmers involved in the study. The ram:ewe ratio was 1:10.

\section{Semen Preparation}

Semen was collected by artificial vagina from 12 Assaf rams of proven fertility maintained at PLDC facilities, Tubas, WB. Only ejaculates with a motility score $>$ 3 , on a scale from 0 to 5 , and a sperm concentration $>$ $2.5 \times 10^{9} / \mathrm{mL}$ were included (O'Hara et al., 2010). Accepted ejaculates were diluted in two different media: egg yolk citrate (glucose $0.8 \mathrm{~g}$; sodium citrate $3.75 \mathrm{~g}$; fresh 
egg yolk $20 \mathrm{~mL}$; distilled water $80 \mathrm{~mL}$ ) or AndroMed (Minitübe, Tiefenbach, Germany). Immediately after dilution, semen was evaluated again for motility. Only diluted semen with a motility score $>3$ were used for the AI. The semen was maintained in a thermos at $15^{\circ} \mathrm{C}$ until arrival at the insemination farm $(2-8 \mathrm{~h})$.

\section{Pregnancy Diagnosis and Reproductive Parameters}

Pregnancy was diagnosed by ultrasound approximately 60 days following TAI or ram exposure, and data on lambing were collected by direct on-farm observation. The reproductive parameters were observed and calculated for:

Pregnancy rate $=$ number of ewes pregnant/number of ewes subjected to AI and/or ram exposure $(\%)$

Parturition rate=number of ewes lambed/number of ewes subjected to AI and/or ram exposure $(\%)$;

Lambing rate $=$ number of lambs born/number of ewes subjected to $\mathrm{AI}$ and/or ram exposure (\%);

Prolificacy =number of lambs born/number of ewes lambing (\%).

\section{Statistical Analysis}

The effects on the observed reproductive parameters of the breeding farms $(n=33)$, flock breed (Awassi, Assaf or crossbreed), breeding protocol and semen extender (EYC, AND, EYC-RR, AND-RR, RAM) were analysed by Fisher's exact test. In addition, in the EYC and AND groups, a second Fisher's exact test was conducted to evaluate the effects on the pregnancy rate of the inseminating ram. Only rams with at least $30 \mathrm{AI}$ were included in the analysis $(n=6)$. Values were considered significant with $\mathrm{p}<0.05$.

\section{RESULTS}

Pregnancy rate, parturition rate, and prolificacy were significantly higher $(p<0.05)$ in the EYC-RR and AND-RR groups than in the EYC and AND groups, while lambing rate was similar among groups (Table 1).

No statistical differences in the above mentioned reproductive parameters were observed between the three different genotypes (Table 2) and breeding farms (Table 3). Moreover, no statistical differences in pregnancy rates were observed among inseminating rams: Ram 1 (14/36, 38.9\%), Ram 2 (14/40, 35.0\%), Ram 3 (25/64, $39.1 \%)$, Ram 4 (12/30, 40.0\%), Ram 5 (12/31, 38.7\%), and Ram 6 (15/41, 36.6\%).

Eighty-nine twins $(37.2 \%)$ and 12 triplets (5\%) lambing were obtained. In one case, four lambs were born from a single dam.

\section{DISCUSSION}

Pregnancy rate after AI in sheep is quite variable according to several factors such as season (breeding or non-breeding), ewes breed, age and management (hormonal treatment or natural estrous), type of semen (fresh, chilled or frozen), time, number and site (cervical or uterine) of insemination, and the skill of operator (Palacín et al., 2012).

In the present study, parturition rate following vaginal AI during the non-breeding season was 32.6\% and $39.3 \%$ in the EYC and AND groups, respectively. These results are similar compared to other studies for fresh diluted semen AIs performed during breeding and non-breeding season: Karagiannidis et al. (2001) re-

Table 1. Pregnancy, parturition, lambing rates, and prolificacy according to the semen extender employed in 575 ewes reared in West Bank

\begin{tabular}{lccccc}
\hline \multirow{2}{*}{ Variables } & \multicolumn{5}{c}{ Experimental groups } \\
\cline { 2 - 6 } & EYC & AND & EYC-RR & AND-RR & RAM \\
\hline Pregnancy rate (\%) & $34.8(46 / 132)^{\mathrm{a}}$ & $40.8(82 / 201)^{\mathrm{a}}$ & $56.1(69 / 123)^{\mathrm{b}}$ & $49.4(39 / 79)^{\mathrm{b}}$ & $40.0(16 / 40)^{\mathrm{ab}}$ \\
Parturition rate (\%) & $32.6(43 / 132)^{\mathrm{a}}$ & $39.3(79 / 201)^{\mathrm{a}}$ & $52.8(65 / 123)^{\mathrm{b}}$ & $46.8(37 / 79)^{\mathrm{b}}$ & $37.5(15 / 40)^{\mathrm{ab}}$ \\
Lambing rate (\%) & $45.5(60 / 132)$ & $57.2(115 / 201)$ & $79.8(98 / 123)$ & $72.2(57 / 79)$ & $60.0(24 / 40)$ \\
Prolificacy (\%) & $139.5(60 / 43)^{\mathrm{a}}$ & $145.6(115 / 79)^{\mathrm{a}}$ & $150.8(98 / 65)^{\mathrm{b}}$ & $154.0(57 / 37)^{\mathrm{b}}$ & $160.0(24 / 15)^{\mathrm{ab}}$ \\
\hline
\end{tabular}

Note: Means in the same row with different superscripts differ significantly $(\mathrm{p}<0.05)$. EYC $=$ AI with semen diluted with egg yolk citrate; AND $=$ AI with semen diluted with AndroMed; EYC- RR= AI with semen diluted with egg yolk citrate plus exposition to rams three hours after AI; AND - RR=AI with semen diluted with Andromed plus exposition to rams three hours after AI; RAM= exposition to rams 48 hours following sponges' removal and PMSG injection.

Table 2. Pregnancy, parturition, lambing rates, and prolificacy according to the breed in 492 ewes reared in West Bank*

\begin{tabular}{lccc}
\hline \multirow{2}{*}{ Variables } & \multicolumn{3}{c}{ Ewes types } \\
\cline { 2 - 4 } & Awassi & Assaf & Crossbred \\
\hline Pregnancy rate (\%) & $45.7(43 / 94)$ & $47.4(108 / 228)$ & $41.7(71 / 170)$ \\
Parturition rate (\%) & $45.7(43 / 94)$ & $45.7(104 / 228)$ & $39.4(67 / 170)$ \\
Lambing rate (\%) & $56.4(53 / 94)$ & $67.1(153 / 228)$ & $65.3(111 / 170)$ \\
Prolificacy (\%) & $123.2(53 / 43)$ & $147.1(153 / 104)$ & $165.7(111 / 67)$ \\
\hline
\end{tabular}

Note: ${ }^{*}$ ) It was not possible to record the breed of 83 ewes. 
Table 3. Pregnancy, parturition, lambing rates, and prolificacy according to the breeding farms ( $\mathrm{n}=33$ ) in 575 ewes reared in West Bank

\begin{tabular}{|c|c|c|c|c|}
\hline \multirow{2}{*}{ Breeding farms } & \multicolumn{4}{|c|}{ Reproductive parameters } \\
\hline & Pregnancy rate (\%) & Parturition rate $(\%)$ & Lambing rate $(\%)$ & Prolificacy (\%) \\
\hline Farm 1 & $30.0(3 / 10)$ & $30.0(3 / 10)$ & $50.0(5 / 10)$ & $166,7(5 / 3)$ \\
\hline Farm 2 & $30.0(6 / 20)$ & $30.0(6 / 20)$ & $45.0(9 / 20)$ & $150.0(9 / 6)$ \\
\hline Farm 3 & $62.5(15 / 24)$ & $54.2(13 / 24)$ & $79.2(19 / 24)$ & $146.2(19 / 13)$ \\
\hline Farm 4 & $30.0(3 / 10)$ & $30.0(3 / 10)$ & $50.0(5 / 10)$ & $166.7(5 / 3)$ \\
\hline Farm 5 & $40.0(4 / 10)$ & $40.0(4 / 10)$ & $50.0(5 / 10)$ & $125.0(5 / 4)$ \\
\hline Farm 6 & $30.0(6 / 20)$ & $30.0(6 / 20)$ & $40.0(8 / 20)$ & $133.3(8 / 6)$ \\
\hline Farm 7 & $50.0(5 / 10)$ & $50.0(5 / 10)$ & $80.0(8 / 10)$ & $160.0(8 / 5)$ \\
\hline Farm 8 & $38.5(10 / 26)$ & $34.6(9 / 26)$ & $46.1(12 / 26)$ & $133.3(12 / 9)$ \\
\hline Farm 9 & $34,6(9 / 26)$ & $26.9(7 / 26)$ & $38.5(10 / 26)$ & $142.9(10 / 7)$ \\
\hline Farm 10 & $30.8(8 / 26)$ & $30.8(8 / 26)$ & $38.5(10 / 26)$ & $125.0(10 / 8)$ \\
\hline Farm 11 & $24.0(6 / 25)$ & $24.0(6 / 25)$ & $40.0(10 / 25)$ & $166.7(10 / 6)$ \\
\hline Farm 12 & $45.0(9 / 20)$ & $45.0(9 / 20)$ & $75.0(15 / 20)$ & $166.7(15 / 9)$ \\
\hline Farm 13 & $35.0(7 / 20)$ & $30.0(6 / 20)$ & $40.0(8 / 20)$ & $133.3(8 / 6)$ \\
\hline Farm 14 & $40.0(8 / 20)$ & $40.0(8 / 20)$ & $70.0(14 / 20)$ & $175.0(14 / 8)$ \\
\hline Farm 15 & $60.0(12 / 20)$ & $50.0(10 / 20)$ & $75.0(15 / 20)$ & $150.0(15 / 10)$ \\
\hline Farm 16 & $35.0(7 / 20)$ & $35.0(7 / 20)$ & $45.0(9 / 20)$ & $128.6(9 / 7)$ \\
\hline Farm 17 & $65.0(13 / 20)$ & $60.0(12 / 20)$ & $85.0(17 / 20)$ & $141.7(17 / 12)$ \\
\hline Farm 18 & $45.0(9 / 20)$ & $45.0(9 / 20)$ & $80.0(16 / 20)$ & $177.8(16 / 9)$ \\
\hline Farm 19 & $50.0(10 / 20)$ & $50.0(10 / 20)$ & $60.0(12 / 20)$ & $120.0(12 / 10)$ \\
\hline Farm 20 & $70.0(7 / 10)$ & $70.0(7 / 10)$ & $120.0(12 / 10)$ & $171.4(12 / 7)$ \\
\hline Farm 21 & $50.0(5 / 10)$ & $50.0(5 / 10)$ & $70.0(7 / 10)$ & $140.0(7 / 5)$ \\
\hline Farm 22 & $40.0(8 / 20)$ & $40.0(8 / 20)$ & $55.0(11 / 20)$ & $137.5(11 / 8)$ \\
\hline Farm 23 & $40.0(4 / 10)$ & $30.0(3 / 10)$ & $50.0(5 / 10)$ & $166.7(5 / 3)$ \\
\hline Farm 24 & $40.0(8 / 20)$ & $40.0(8 / 20)$ & $60.0(12 / 20)$ & $150.0(12 / 8)$ \\
\hline Farm 25 & $47.4(9 / 19)$ & $42.1(8 / 19)$ & $57.9(11 / 19)$ & $137.5(11 / 8)$ \\
\hline Farm 26 & $40.0(8 / 20)$ & $30.0(6 / 20)$ & $50.0(10 / 20)$ & $166.7(10 / 6)$ \\
\hline Farm 27 & $47.4(9 / 19)$ & $42.1(8 / 19)$ & $52.6(10 / 19)$ & $125.0(10 / 8)$ \\
\hline Farm 28 & $45.0(9 / 20)$ & $40.0(8 / 20)$ & $50.0(10 / 20)$ & $125.0(10 / 8)$ \\
\hline Farm 29 & $60.0(6 / 10)$ & $60.0(6 / 10)$ & $100.0(10 / 10)$ & $166.7(10 / 6)$ \\
\hline Farm 30 & $70.0(7 / 10)$ & $50.0(5 / 10)$ & $90.0(9 / 10)$ & $180.0(9 / 5)$ \\
\hline Farm 31 & $90.0(9 / 10)$ & $60.0(6 / 10)$ & $100.0(10 / 10)$ & $166.7(10 / 6)$ \\
\hline Farm 32 & $70.0(7 / 10)$ & $70.0(7 / 10)$ & $100.0(10 / 10)$ & $142.9(10 / 7)$ \\
\hline Farm 33 & $75.0(15 / 20)$ & $65.0(13 / 20)$ & $100.0(20 / 20)$ & $153.8(20 / 13)$ \\
\hline
\end{tabular}

ported a mean $44 \%$ parturition rate in 2,567 indigenous Greek ewes inseminated twice during the non-breeding season; Anel et al. (2005) observed a parturition rate between $23 \%$ and $35 \%$, mean $31 \%$, out of 17,631 vaginal $\mathrm{AI}$ of Churra ewes in Spain, according to the farm, season, age of the ewes, and lambing-insemination interval. Álvarez et al. (2012) observed a parturition rate between $27 \%$ and $48 \%$ in 465 inseminated Assaf and Churra sheep in Spain, depending on the breed and the catheter employed for AI but not on the degree of cervical penetration.

It is worldwide accepted that laparoscopic AI is followed by a higher pregnancy and lambing rates than vaginal AI, mostly when frozen-thawed semen is employed, in ewes (Anel et al., 2005; Baril et al., 1993; O'Hara et al., 2010). Laparoscopic AI, however, is expensive, requires technical expertise, raises concerns for animal welfare (O'Hara et al., 2010) and needs good management and strict hygienic conditions. Laparoscopic
AI, as well as the use of frozen-thawed semen, is, at the moment, far to apply to the condition of sheep breeding in WB.

In this study, two different semen extenders were employed: the first one, egg yolk citrate, derivate from the medium employed in Russia since the last century and was routinely used at PLDC since several years; the second one, AndroMed, (Minitübe, Tiefenbach, Germany) is a relatively new commercial medium, without egg yolk or other animal derivate elements, and containing soybean lecithin. The reproductive parameters observed in semen diluted with AndroMed (AND group) were higher than those in semen diluted with egg yolk citrate (EYC group), but the differences were not statistically significant. Similarly, Masoudi et al. (2017) reported that semen quality and fresh and frozen semen fertility were similar in ram semen diluted with media containing soybean lecithin or egg yolk. Our results confirm that AndroMed is a suitable medium to 
dilute ram semen for liquid storage and AI, preventing potential problems related to the variability of egg yolk quality including possible contaminations. Nevertheless, buying AndroMed from the market is much more expensive than preparing media at home and this has to be taken into account, especially when working in a poor economic condition as is the case of sheep breeding in WB. In the present study, the reproductive performance of ewes submitted to vaginal AIs (EYC and AND groups) were not statistically different from those bred with natural matings (RAM group). Similar results in reproductive parameters between vaginal AI and natural mating were previously observed by Tabbaa et al. (2008) in Awassi ewes during the breeding season. Nevertheless, pregnancy and parturition rates observed in the present study with natural mating, close to $40 \%$ in the RAM group and 50\% in AI reinforced by ram groups (EYC-RR, AND-RR), that were lower than expected. In Syria, Zarkawi et al. (1999) reported a parturition rate of $80 \%$ and a prolificacy of $137.5 \%$ for Awassi ewes submitted to natural mating outside the breeding season after an estrous synchronization protocol similar to that employed in the present study. Similarly, Ozyurtlu et al. (2010) reported a parturition rate around 70\%, a lambing rate around $80 \%$, and a prolificacy of $111.7 \%$ in Awassi ewes submitted to estrous synchronization and natural mating during the non-breeding season, in Turkey. In these two papers, the percentages of ewes in estrous after progesterone withdrawal were between 82 and 90\% (Ozyurtlu et al., 2010; Zarkawi et al., 1999). In the present study, the attainment of estrous after the hormonal treatment was not evaluated, but all the ewes were inseminated and/or joined to the rams and all were included in the analysis of the results. Despite the efforts done to select breeders with the highest standard of animal management, it is unquestionable that the animal breeding conditions in WB are not optimal at least due to the general difficult access to water and the common unavailability of suitable facilities and, mostly during the dry season, of a sufficient amount of fodder. As it is known that the incidence and the depth of anestrous, in seasonally-breeder animals, are related to the management quality, it seems possible to explain the low fertility after natural mating with a probably high proportion of ewes in deep anestrous at the sponges application time. It is well known that seasonal breeder animals are less responsive to pharmacologic estrous induction and ovulation in deep anestrous when the release of gonadotropins at the pituitary level is very scarce. Moreover, in this study it was not possible to perform any segregation between males and females before the breeding period to get the benefit of the "male effect" (Fabre-Nys et al., 2016). Taking into account these sub-optimal rearing conditions in $\mathrm{WB}$, it is possible to explain the low fertility observed in this study either after AI or natural mating. The amount of PMSG generally recommended in sheep varies from 250 to 600 IU (Baril et al., 1993). In this study, the use of 600 IU of PMSG, a relatively large dose, was followed by a satisfactory prolificacy and a low incidence of parturitions of more than two lambs: $5 \%$ of triplet and only one case of quadruplet.
In the present study, the reproductive performances in the EYC-RR and AND-RR groups were significantly higher than in the EYC and AND groups. Exposing ewes to the rams 3 hours after AI precluded the possibility to know the paternity of the new-born lambs, but significantly improved the immediate productivity of sheep. Given the current state of the economy in West Bank, it is probably more important for most breeders to increase the productivity than implementing a genetic improvement program.

The breeding farm has been broadly indicated as a crucial factor having a considerable impact on the success of AI and natural mating (Anel et al., 2005; Paulenz et al., 2010; Palacín et al., 2012). This effect has been hypothesized to be the result of the interaction between many farm factors, including management, feeding regimen, and human-interaction (Anel et al., 2005). In the present study, no statistical differences in reproductive performances between breeding farms were evident, but pregnancy rates ranged from $\leq 30 \%$ ( $N=5$ farms) to $\geq 60 \%$ ( $N=9$ farms), with the other 19 farms within this range. Probably, the low number of ewes inseminated per farm made impossible to evidentiate statistical differences.

Variations in ram fertility have been previously observed in ewes inseminated with fresh semen (Anel et al., 2005; Palacín et al., 2012). In the present study, differences in pregnancy rate between inseminating rams were not observed (range 35.0\%-40.0\%). This might be due to the strict selection of rams and ejaculates employed, the homogeneous management of rams, and/or the low number of AIs performed per ram.

\section{CONCLUSION}

In conclusion, TAI with fresh semen diluted either with egg yolk citrate or with AndroMed seems to be an effective and feasible tool to increase lamb production and improve genetic merits of the sheep population out of the breeding season in WB. Besides, exposing ewes to the rams $3 \mathrm{~h}$ after TAI may be a useful technique to increase the immediate reproductive performances of the sheep, but precludes the possibility to know the paternity of the new-born lambs. However, in the actual conditions of the WB, for most breeders, it is probably more important to look for immediate return (some lambs more to sell today) than adopting longer term approach (a good flock tomorrow).

\section{CONFLICT OF INTEREST}

We certify that there is no conflict of interest with any financial, personal, or other relationships with other people or organization related to the material discussed in the manuscript.

\section{ACKNOWLEDGEMENT}

Authors acknowledge the staff of PLDC for technical support and for the effort done to meet the demands of Italian researchers and the Palestinian breeders for 
the great hospitality. This project was co-funded by the Italian Ministry of Foreign Affairs and International Cooperation and managed by Oxfam Italy.

\section{REFERENCES}

Abecia, J. A., F. Forcada, \& A. Gonzalez-Bulnes. 2012. Hormonal control of reproduction in small ruminants. Anim. Reprod. Sci. 130:173-179. https://doi.org/10.1016/j. anireprosci.2012.01.011

Álvarez, M., C. A. Chamorro, M. Kaabi, L. Anel-López, J. C. Boixo, E. Anel, L. Anel, \& P. de Paz. 2012. Design and "in vivo" evaluation of two adapted catheters for intrauterine transcervical insemination in sheep. Anim. Reprod. Sci. 131:153-159. https://doi.org/10.1016/j. anireprosci.2012.03.001

Anel, L., M. Kaabi, B. Abroug, M. Alvarez, E. Anel, J. C. Boixo, L. F. De La Fuente, \& P. De Paz. 2005. Factors influencing the success of vaginal and laparoscopic artificial insemination in Churra ewes: A field assay. Theriogenology 63:12351247. https://doi.org/10.1016/j.theriogenology.2004.07.001

Baril, G., P. Chemineau, Y. Cognie, Y. Guerin, B. Leboeuf, P. Orgeur, \& J. C. Vallet. 1993. Manuel de formation pourl'inséminationartificielle chez les ovins et les caprins. Organisation des Nations Unies pour l'alimentation et l'agriculture, Rome.

Fabre-Nys, C., A. Chanvallon, J. Dupont, L. Lardic, D. Lomet, S. Martinet, \& R. J. Scaramuzzi. 2016. The "Ram Effect": A "Non-Classical" mechanism for inducing LH surges in sheep. PLOS ONE 11:e0158530. https://doi.org/10.1371/ journal.pone.0158530

Fleisch, A., H. Bollwein, M. Piechotta, \& F. Janett. 2015. Reproductive performance of Lacaune dairy sheep exposed to artificial long days followed by natural photoperiod without and with additional progestagen treatment during the nonbreeding season. Theriogenology 83:320325. https://doi.org/10.1016/j.theriogenology.2014.06.031

Gonzalez-Bulnes, A., A. Menchaca, G. B. Martin, \& P. Martinez-Ros. 2020. Seventy years of progestagen treatments for management of the sheep oestrous cycle: Where we are and where we should go. Reprod. Fertil. Dev. 32:441-452. https://doi.org/10.1071/RD18477

Gootwine, E. 2011. Mini review: Breeding Awassi and Assaf sheep for diverse management conditions. Trop. Anim. Health Prod. 43:1289-1296. https://doi.org/10.1007/ s11250-011-9852-y

Islam, R. \& M. Z. Khan. 2010. Preservation of ram semen with egg yolk citrate extender at refrigeration temperature. Indian Vet. J. 87:463-465.

Karagiannidis, A., S. Varsakeli, G. Karatzas, \& C.Brozos. 2001. Effect of time of artificial insemination on fertility of progestagen and PMSG treated indigenous greek ewes, during non-breeding season. Small Rumin. Res. 39:67-71. https:// doi.org/10.1016/S0921-4488(00)00170-X

Khalifa, T., A. Lymberopoulos, \& E. Theodosiadou. 2013. Association of soybean-based extenders with field fertility of stored ram (Ovisaries) semen: A randomized doubleblind parallel group design. Theriogenology 79:517-527. https://doi.org/10.1016/j.theriogenology.2012.11.009

Krishnakumar, S., D. P. Whiteside, B. Elkin, \& J. C. Thundathil. 2011. Evaluation of an animal protein-free semen extender for cryopreservation of epididymal sperm from North
American bison (Bison bison). Theriogenology 76:252-260. https://doi.org/10.1016/j.theriogenology.2011.02.001

Layek, S. S., T. K. Mohanty, A. Kumaresan, \& J. E. Parks. 2016. Cryopreservation of bull semen: Evolution from egg yolk based to soybean-based extenders. Anim. Reprod. Sci. 172:1-9. https://doi.org/10.1016/j.anireprosci.2016.04.013

Martin, G. B., \& T.R. Ferasyi. 2016. Clean, green, ethical (CGE) management: what research do we really need?. Int. J. Trop. Vet. Biomed. Res. 1:1-9. https://doi.org/10.21157/ijtvbr.v1i1.5066

Masoudi, R., A. ZareShahneh, A. Towhidi, H. Kohram, A. Akbarisharif, \& M. Sharafi. 2017. Fertility response of artificial insemination methods in sheep with fresh and frozen-thawed semen. Cryobiology 74:77-80. https://doi. org/10.1016/j.cryobiol.2016.11.012

O'Hara, L., J. P. Hanrahan, L. Richardson, A. Donovan, S. Fair, A. C. O. Evans, \& P. Lonergan. 2010. Effect of storage duration, storage temperature, and diluent on the viability and fertility of fresh ram sperm. Theriogenology 73:541549. https://doi.org/10.1016/j.theriogenology.2009.10.009

Ozyurtlu, N., I. Kucukaslan, \& Y. Cetin. 2010. Characterization of oestrous induction response, oestrous duration, fecundity and fertility in Awassi ewes during the non-breeding season utilizing both CIDR and intravaginal sponge treatments. Reprod. Domest. Anim. 45:464-467. https://doi. org/10.1111/j.1439-0531.2008.01246.x

Palacín, I., J. L. Yániz, E. Fantova, M. E. Blasco, F. J. QuintínCasorrán, E. Sevilla-Mur, \& P. Santolaria. 2012. Factors affecting fertility after cervical insemination with cooled semen in meat sheep. Anim. Reprod. Sci. 132:139-144. https://doi.org/10.1016/j.anireprosci.2012.05.005

Palestinian Central Bureau of Statistics. 2013. Announces the main results for Livestock Survey. http://www.pcbs.gov. ps/site/512/default.aspx?tabID=512\&lang=en\&ItemID=107 $3 \& \operatorname{mid}=3171 \&$ wversion=Staging [10 April 2017].

Paulenz, H., T. Adnoy, O. H. Fossen, \& L. Soderquist. 2010. Effect on field fertility of addition of gelatine, different dilution rates and storage times of cooled ram semen after vaginal insemination. Reprod. Domest. Anim. 45:706-710. https://doi.org/10.1111/j.1439-0531.2008.01338.x

Stefanov, R. G., G. Anev, \& D. V. Abadjieva. 2015. Effect of different extenders and storage periods on motility and fertility of ram sperm. Mac. Vet. Rev. 38:1-5. https://doi. org/10.14432/j.macvetrev.2014.12.036

Tabbaa, M. J., M. A. Alnimer, M. Shboul, \& H. H. Titi. 2008. Reproductive characteristics of Awassi ewes mated artificially or naturally to Jordanian or Syrian Awassi rams. Anim. Reprod. 5:23-29.

Talafha, A. Q. \& M. M. Ababneh. 2011. Awassi sheep reproduction and milk production. Trop. Anim. Health Prod. 43:1319-1326. https://doi.org/10.1007/s11250-011-9858-5

WFP and FAO. 2010. Socio Economic and Food Security Survey: West Bank and Gaza Strip, Occupied Palestinian Territory. http://documents.wfp.org/stellent/groups/public/documents/ena/wfp232398.pdf [10 April 2017].

Zamiri , M. J. 2020. Update on semen cryopreservation in sheep and goats: A review. J. Anim. Sci. Technol. 8:01-15.

Zarkawi, M., M. R. Al-Merestani, \& M. F. Wardeh. 1999. Induction of synchronized oestrous and early pregnancy diagnosis in Syrian Awassi ewes, outside the breeding season. Small Rumin. Res. 33:99-102. https://doi.org/10.1016/ S0921-4488(99)00007-3 